\title{
Monoallelic but not biallelic loss of Dicer1 promotes tumorigenesis in vivo
}

\author{
I Lambertz ${ }^{1}$, D Nittner ${ }^{1}$, P Mestdagh ${ }^{2}$, G Denecker ${ }^{1}$, J Vandesompele ${ }^{2}$, MA Dyer ${ }^{3}$ and J-C Marine ${ }^{\star, 1}$
}

Human tumors are characterized by widespread reduction in microRNA (miRNA) expression, although it is unclear how such changes come about and whether they have an etiological role in the disease. Importantly, miRNA knockdown has been shown to enhance the tumorigenic potential of human lung adenocarcinoma cells. A defect in miRNA processing is one possible mechanism for global downregulation. To explore this possibility in more detail in vivo, we have manipulated Dicer1 gene dosage in a mouse model of retinoblastoma. We show that although monoallelic loss of Dicer1 does not affect normal retinal development, it dramatically accelerates tumor formation on a retinoblastoma-sensitized background. Importantly, these tumors retain one wild-type Dicer1 allele and exhibit only a partial decrease in miRNA processing. Accordingly, in silico analysis of human cancer genome data reveals frequent hemizygous, but not homozygous, deletions of DICER1. Strikingly, complete loss of Dicer1 function in mice did not accelerate retinoblastoma formation. miRNA profiling of these tumors identified members of the let-7 and miR-34 families as candidate tumor suppressors in retinoblastoma. We conclude that Dicer1 functions as a haploinsufficient tumor suppressor. This finding has implications for cancer etiology and cancer therapy.

Cell Death and Differentiation (2010) 17, 633-641; doi:10.1038/cdd.2009.202; published online 18 December 2009

A large body of evidence indicates that alterations in the expression of microRNAs (miRNAs) contribute to cancer pathologies. ${ }^{1}$ miRNAs function as agents of the RNA interference pathway to silence their cognate coding target genes either by cleaving mRNA molecules or by inhibiting their translation. ${ }^{2}$ By silencing tumor-suppressive and oncogenic mRNAs, miRNAs themselves can function as oncogenes or tumor suppressors, respectively. ${ }^{3}$ The let-7 family, for instance, limits lung tumorigenesis through inhibition of several oncogenes including members of the Ras family or HMGA2. ${ }^{4,5}$

Initial efforts to link miRNAs with cancer were based on expression analyses in which tumors were compared with normal tissues. Such expression profiling analyses revealed the characteristic miRNA signatures of human cancers. ${ }^{6}$ Surprisingly, they also highlighted an overall downregulation of mature miRNAs in several types of mouse and human cancers. ${ }^{7}$ This observation raised two important questions: (i) one of causality - is there a causative link between global downregulation of miRNAs and cancer progression or is the downregulation a byproduct of tumor development? and (ii) one of mechanism - what are the molecular mechanisms and the genetic events underlying such widespread changes in tumors? The first question was addressed by RNAi targeting of factors involved in miRNA maturation, such as DICER1 and DROSHA, showing that global downregulation of miRNA processing increased the transforming properties of a lung adenocarcinoma cell line in in vitro culture assays and in xenograft experiments. ${ }^{8}$ Widespread silencing of miRNA expression was proposed to be, at least partly, a consequence of Myc-mediated transcriptional repression; ${ }^{9}$ however, the data also raised the possibility that DICER1 might be a target of genetic disruption in human cancers. Surprisingly, however, although reduced levels of DICER1 have been reported in tumors, ${ }^{10,11}$ no loss-of-function mutations in DICER1 have been reported to date. There have, however, been reports of truncating mutations in TARBP2, encoding an integral component of a DICER1-containing complex, in sporadic and hereditary carcinomas with microsatellite instability. ${ }^{12}$ Frameshift mutations in TARBP2 diminished TRBP protein expression and caused a partial defect in the processing of miRNAs. Importantly, the TRBP impairment is associated with a partial destabilization of the DICER1 protein. These data raised the possibility that Dicer downregulation rather than its complete loss of function is selected for during tumorigenesis.

To directly address this question, we manipulated Dicer1 (referred hereafter as Dic) gene dosage in a mouse model of retinoblastoma. As germline inactivation of Dic in mice causes an early embryonic lethal phenotype ${ }^{13}$ we specifically inactivated $\mathrm{Dic}$ in retinoblasts by combining a conditional floxed allele of Dic ${ }^{14}$ with the retinal Chx10Cre transgenic line. ${ }^{15}$ We chose this genetic model system for two main reasons. First, Chx10Cre-mediated inactivation of one Dic allele decreases the production of mature miRNAs without affecting retinogenesis. ${ }^{16}$ Second, the Chx10Cre mice have

\footnotetext{
${ }^{1}$ Laboratory for Molecular Cancer Biology, VIB-UGent, Ghent B9052, Belgium; ${ }^{2}$ Center for Medical Genetics, Ghent University Hospital, Ghent B9000, Belgium and ${ }^{3}$ Department of Developmental Neurobiology, St. Jude Children's Research Hospital, Memphis, TN 38105, USA

*Corresponding author: J-C Marine, Laboratory for Molecular Cancer Biology, Flanders Interuniversity Institute for Biotechnology, 927 Technologiepark, Ghent B-9052, Belgium. Tel: + 320933 13640; Fax: + 320933 13516; E-mail: chris.marine@dmbr.ugent.be

Keywords: Dicer; microRNA; retinoblastoma; tumor suppressor; haploinsufficiency

Abbreviations: miRNA, microRNA

Received 13.11.09; accepted 23.11.09; Edited by G Melino; published online 18.12.09
} 
been used to create the first preclinical mouse model of retinoblastoma. ${ }^{17,18}$ Chx10Cre-mediated inactivation of the Retinoblastoma $(R b)$ gene leads to inappropriate exit from the cell cycle of retinal progenitor cells and a block in rod maturation. ${ }^{19}$ These mice do not develop retinoblastoma as expression of another $\mathrm{Rb}$ family member, p107, increases in a compensatory manner. ${ }^{18}$ However, on a p107-null background, retinal $\mathrm{Rb}$ inactivation (Chx10Cre; $R b^{\text {lox/lox }} \mathrm{p} 107^{-1-}$ ) leads to the formation of early hyperproliferative lesions, ${ }^{17}$ which are often referred to as retinomas. ${ }^{20}$ Importantly, these lesions rarely go on to become aggressive and invasive tumors and only do so in older animals, suggesting that additional oncogenic lesions are required for full-blown tumorigenesis. For example, conditional inactivation of p53 in mice is one mechanism through which these lesions can progress into aggressive retinoblastoma. ${ }^{17}$ Accordingly, amplification and overexpression of MDMX, a key negative regulator of $\mathrm{p} 53$, is a frequent event that is selected during human retinoblastoma formation. ${ }^{21,22}$

\section{Results}

We first confirmed that specific loss of one Dic allele in retinal progenitor cells does not affect normal retinal development. As expected, histological analysis of the retinae of several Chx10Cre; Dic ${ }^{\text {lox/+ }}$ mice at various stages of postnatal development did not reveal any morphological abnormalities (Figure 1). Strikingly, however, on the retinoblastomasensitized background, loss of one Dic allele dramatically accelerated tumor formation (Figure 2a). Virtually all Chx10Cre; $R b^{\text {lox/lox }} p 107^{/-} ;$Dic ${ }^{\text {lox/+ }}$ mice develop aggressive and invasive intraocular retinoblastoma (Figure $2 b$ and $c$ ), with an average time to visible tumors of 180 days (Figure 2a). Half of these mice had anterior chamber invasion that was clearly visible by 10 weeks of age. By contrast, Chx10Cre; $R b^{\text {lox/lox }} p 107^{/ /-} ; \mathrm{Dic}^{+/+}$developed retinoblastoma only with slow and inconsistent kinetics (Figure 2a). Moreover, although more than $30 \%$ of Chx $10 \mathrm{Cre} ; \mathrm{Rb}^{\text {lox/lox }} \mathrm{p} 107^{/-} ; \mathrm{Dic}^{\text {lox/+ }}$ mice had developed bilateral retinoblastoma with clear evidence of

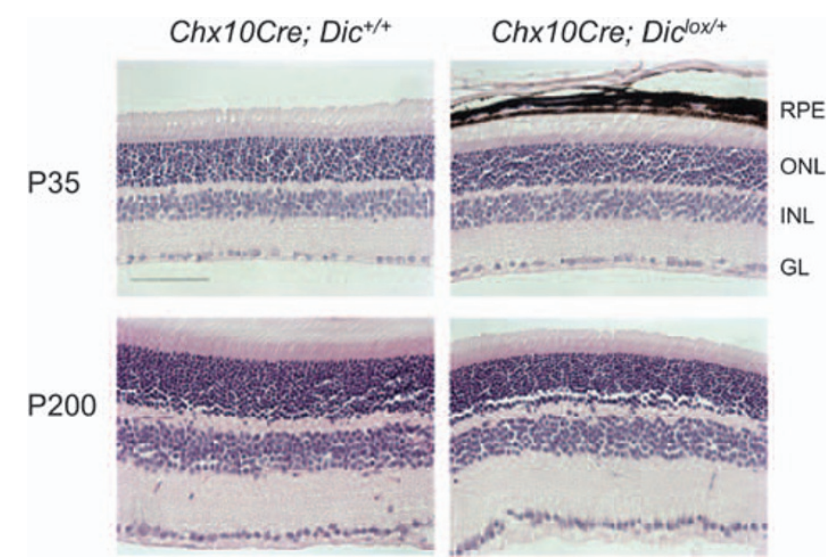

Figure 1 Loss of one copy of Dicer1 does not affect retinogenesis. Hematoxilineosin stain of P35 and P200 retinae show normal retinal lamination in Chx10Cre; $\mathrm{Dic}^{\mathrm{lox} /+}$ mice. Abbreviations: ONL, outer nuclear layer; RPE, retinal pigment epithelium; INL, inner nuclear layer; GL, ganglion layer. Scale bars $=40 \mu \mathrm{m}$ anterior chamber invasion, Chx10Cre; $R b^{\text {lox/lox }} p 107^{-1-}$; $\mathrm{Dic}^{+/+}$mice only ever developed unilateral tumors (data not shown). Finally, metastatic tumors that had invaded local tissues outside the eye through the optic nerve were only

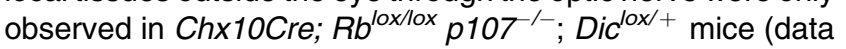
not shown).

We next examined the retinae histologically at postnatal days P35 and onwards. As previously described, ${ }^{18}$ the retinal cytoarchitecture of Chx10Cre; $\mathrm{Rb}^{\text {lox/lox }}{\mathrm{p} 107^{/-}}^{-} \mathrm{Dic}^{+/+}$at P35 is slightly disrupted because of the focal expansion of immature cells from the inner nuclear layer (INL) and their protrusion through the outer plexiform layer (OPL) (Figure 1c). In addition, defects in the maturation of the rod photoreceptors lead to a hypocellular outer nuclear layer (ONL), although the three nuclear layers are still detected in these mice. In contrast, the three nuclear layers can no longer be distinguished in the Dic heterozygous mutants (Figure 2c). The laminar organization in Chx10Cre; $\mathrm{Rb}^{\text {lox/lox }} \mathrm{p} 107^{-/-} ; \mathrm{Dic} \mathrm{Cox}^{\mathrm{lo}+}$ retinae was focally disrupted severely, with immature cells from the INL invading the OPL and extending up to the apical surface of the retina. This resulted in the disruption of the interaction between photoreceptor outer segments and the retinal pigment epithelium (RPE) and focally to dramatic ONL hypocellularity, presumably as a consequence of photoreceptor cell death. The focal nature of the phenotype is consistent with the previously reported mosaic expression pattern of Cre in Chx10Cre transgenic mice. ${ }^{15,23}$ Beyond P35, larger dysplastic lesions, found mainly at the periphery $(6 / 7$ eyes analyzed), seeded the vitreous (Figure 2c, P60) and eventually invaded the anterior chamber of the eye (Figure $2 \mathrm{c}$, P200). The lesions contained Homer-Wright rosettes (Figure 2c), which consist of a radial arrangement of cells around a central tangle of neuronal processes. Interestingly, these histological structures are often found in a subset of human retinoblastomas. ${ }^{24}$

This histopathological analysis indicated that the phenotype observed in Chx10Cre; $\mathrm{Rb}^{\text {lox/lox }} \mathrm{p} 107^{-/-}$; $\mathrm{Dic}$ lox/+ retinae is similar in nature but is significantly more severe than that observed in Chx10Cre; $R b^{\text {lox/lox }} p 107^{-/}$retinae. We therefore hypothesized that the dysplasia and the partial degeneration observed in Dic heterozygous retinae might result from severe expansion of a pool of retinal progenitor cells that normally reside in the INL. Accordingly, immunostaining showed that the cells that disrupted synaptogenesis in the OPL and extended all the way to the apical surface of the retinae expressed the progenitor cell markers Syntaxin and Chx10 $25-27$ (Figure 3). The early tumors also stained for Calretinin, which labels a subset of amacrine and ganglion cells. However, Calretinin expression was less abundant than Syntaxin, more scattered and variable from animal to animal (data not shown). Calbindin, which labels horizontal cells and a subset of amacrine cells weakly, was either expressed at very low levels or undetectable in Chx10Cre; $R b^{\text {lox/lox }}{\mathrm{p} 107^{-1-} ; \mathrm{Dic}}^{\mathrm{lox} /+}$ early lesions (data not shown). Together, these data indicate that the lesions are composed of retinal progenitor cells biased toward the amacrine cell fate. Importantly, these immature cells were GFP-positive and therefore Cre-positive (Figure 3). Cre was fused to GFP in the Chx 10Cre transgenic mice, ${ }^{15}$ so that Cre-positive cells can be identified using anti-GFP antibodies. 

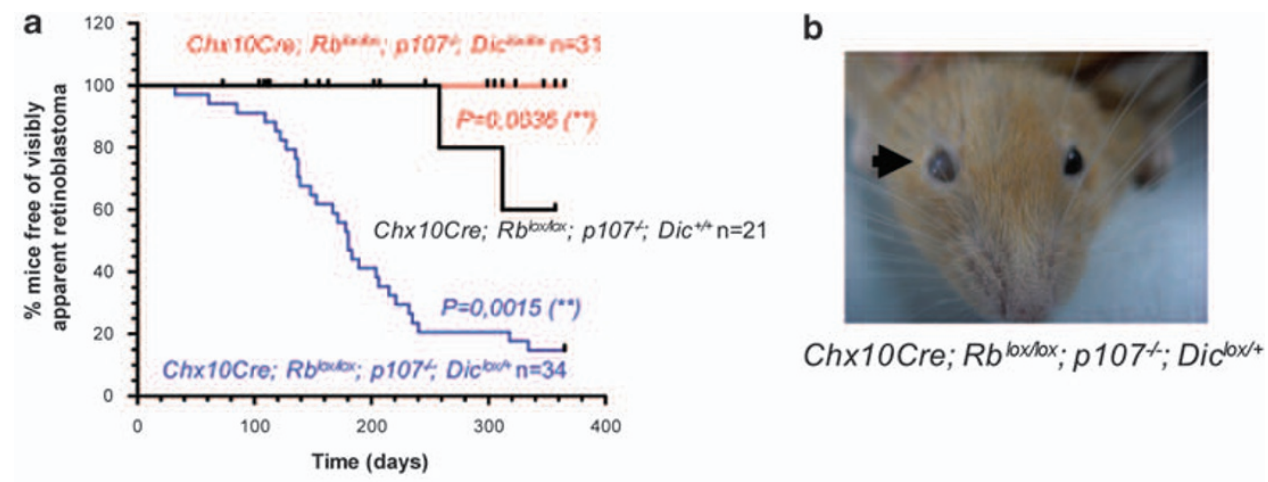

C

Dic $^{+/+}$
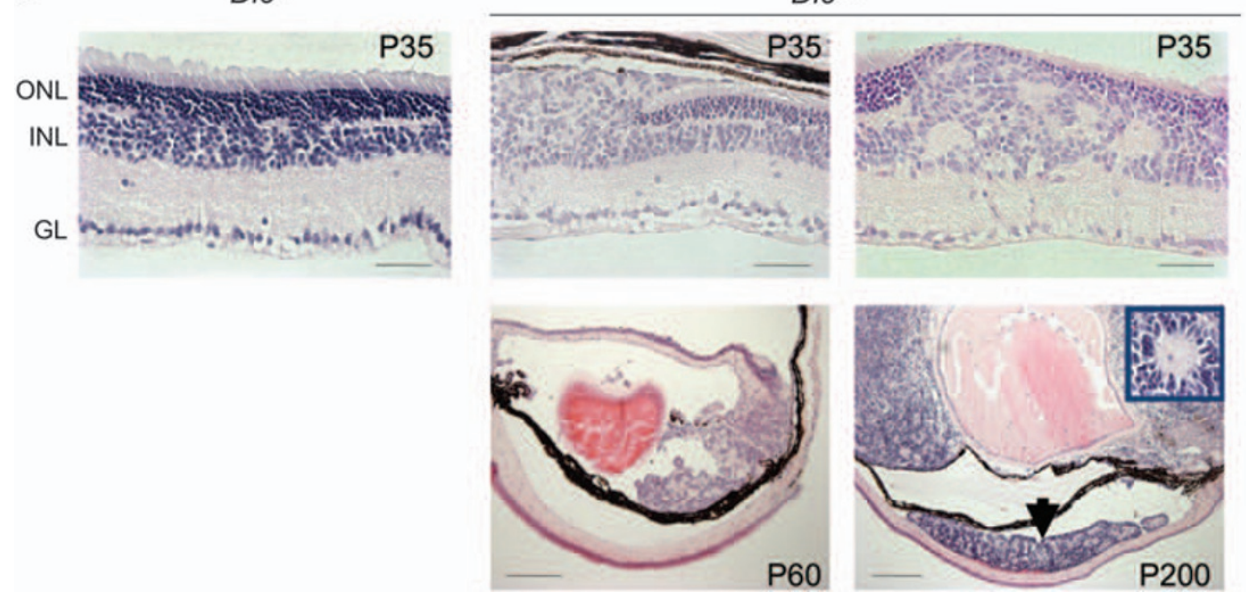

Figure 2 Dicer1 (Dic) heterozygosity enhances tumorigenesis on a retinoblastoma-sensitized background. (a) Kaplan-Meier curve showing the time to first observation of

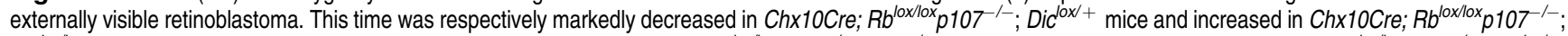

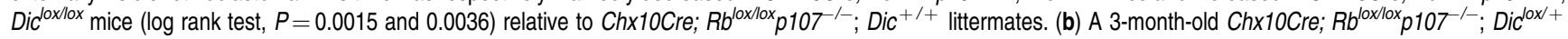
mouse with aggressive retinoblastoma. (c) Hematoxylin and eosin stain with the three retinal nuclear layers (GL: ganglion layer; INL: inner nuclear layer; ONL: outer nuclear layer) indicated. Early retinoblastoma lesions at P35 and invasive tumors seeding the vitreous at P60 are found in $\mathrm{Chx} 10 \mathrm{Cre} ; \mathrm{Rb}^{\mathrm{lox} / \mathrm{ox}} \mathrm{p} 107^{-1-} ; \mathrm{Dic} \mathrm{c}^{\mathrm{lox} /+}$ mice. P200 shows late stage retinoblastoma that had filled the vitreous and the anterior chambers (arrow). Inset: a representative Homer-Wright rosette found in Chx10Cre; $R b^{10 x / 10 x} p 107^{-/-} ;$Dic ${ }^{\text {lox } /+}$ tumors. Scale bars in the top panels $=40$ and $=200 \mu \mathrm{m}$ in the lower panels
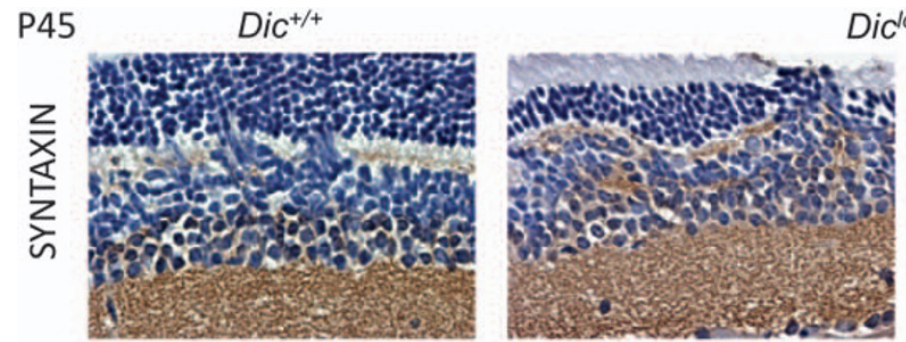

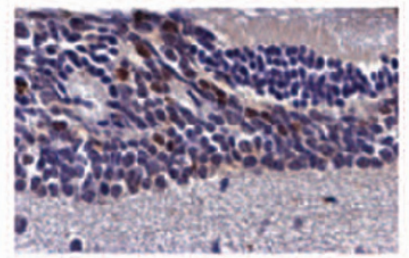

$\mathrm{CHX10}$
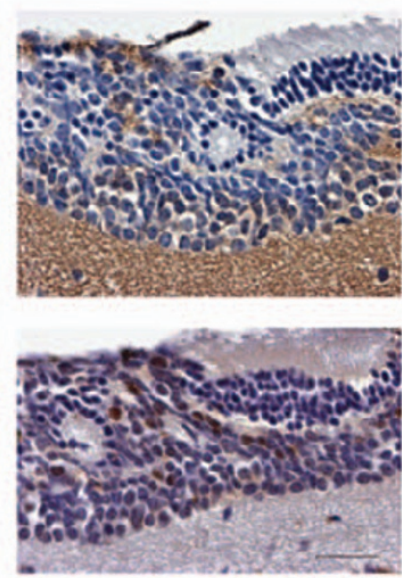

GFP

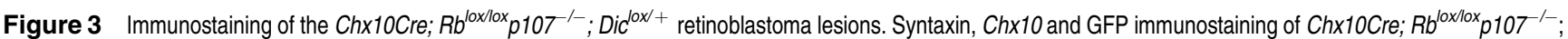

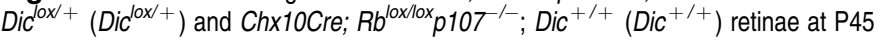


As inappropriate expansion of the immature retinal cells could be a consequence of increased cell proliferation and/or survival, we measured cell proliferation and apoptosis using immunohistochemical assays. As previously reported, we found extensive BrdU incorporation in Chx10Cre; $R b^{\text {lox/lox }} p 107^{-/-}$retinae at $\mathrm{P} 14$, a time when retinogenesis is normally complete. This phenotype was significantly exacerbated in Chx10Cre; $\mathrm{Rb}^{\text {lox/lox }} \mathrm{p} 107^{-/} ; \mathrm{Dic}^{\text {lox/+ }}$ retinae (Figure $4 \mathrm{a}$ and b). Importantly, BrdU-positive cells were localized to the regions containing the GFP immunopositive cells and to where lamination was disrupted. These regions were also strongly positive for the proliferation marker Ki67 (Figure 4a and c). BrdU- and Ki67-positive cells were found in all early dysplastic lesions and late (i.e., P200) retinoblastoma tumors (data not shown). Inappropriate cell proliferation leads to increased apoptosis in Chx10Cre; $R b^{\text {lox/lox }} p 107^{/-}$ retinae. ${ }^{17}$ Accordingly, active capase-3-positive cells could be detected in the Chx10Cre; $R b^{\text {lox/lox }} p 107^{-1-}$ retinae a

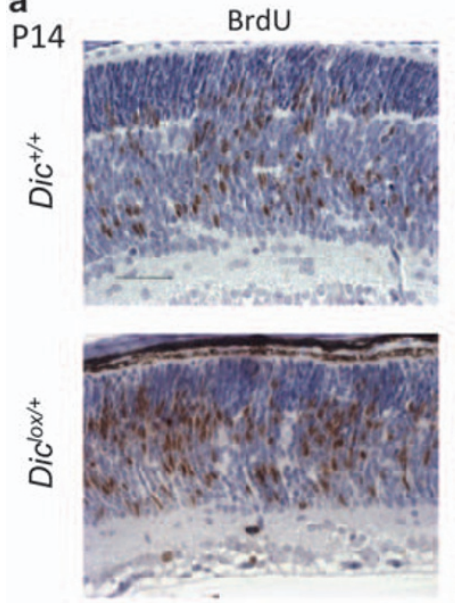

C

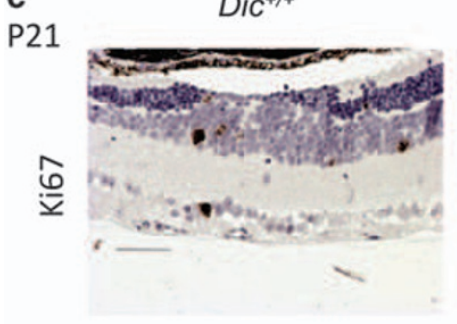

d
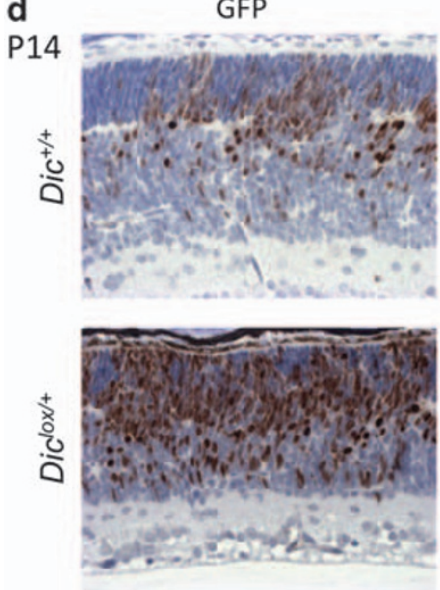

Ki67
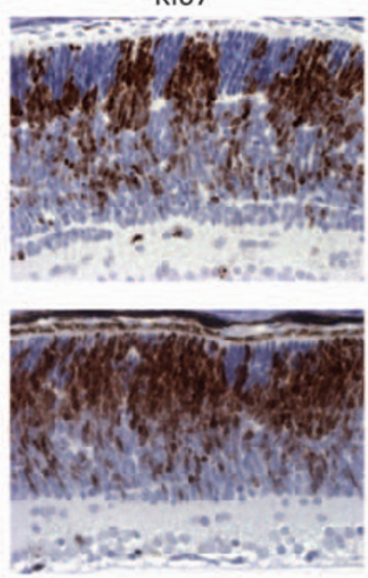

Dic $^{\text {lox/+ }}$

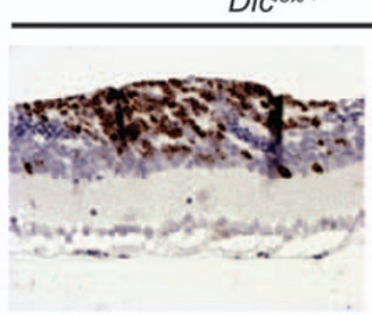

Casp3*
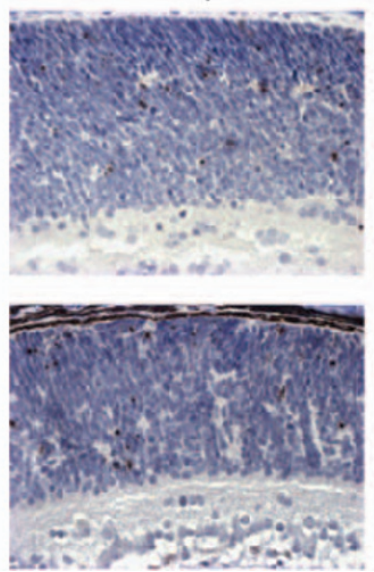

b
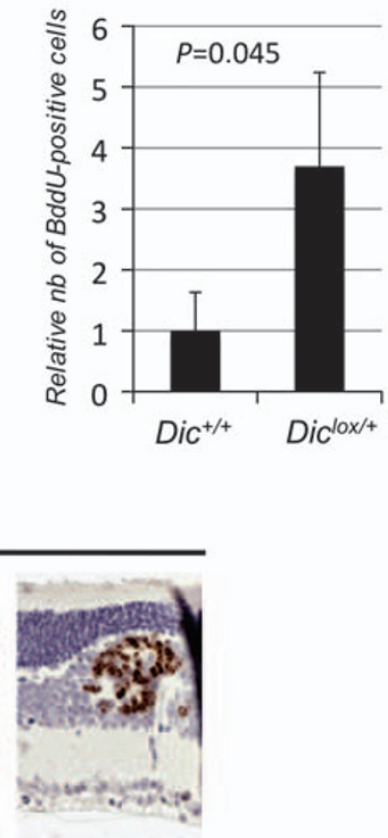

e

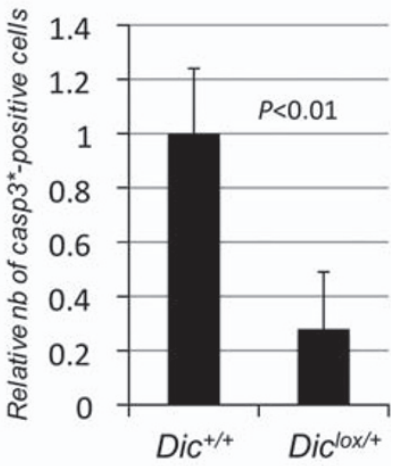

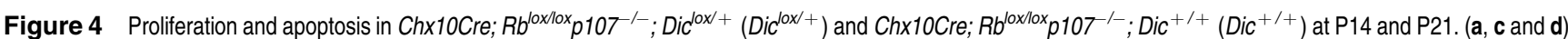
BrdU incorporation, Ki67 and active Caspase3 immunostaining. Scale bars $=40 \mu \mathrm{m}$. Quantification of BrdU (b) and Caspase3 (c) staining was performed on horizontal serial

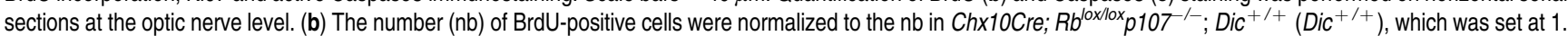
(e) The number of immunoreactive cells to active Caspase3 staining were normalized to the number of GFP-positive cells in serial consecutive sections. The data are

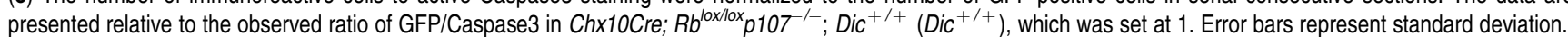
$P$-values (Student's t-test; $N=3$ ) 
(Figure 4d). There was no significant decrease per se in the number of cleaved caspase-3-positive cells in the Chx10Cre; $R b^{\text {lox/lox }} p 107^{-1-} ;$ Dic ${ }^{\text {lox/+ }}$ retinae. However, as the number of GFP-positive cells is increased in these retinae compared with the Chx10Cre; $R b^{\text {lox/lox }} p 107^{/-}$retinae, the data indicate that the number of dying Cre-positive cells is reduced proportionally in the Dicer1 heterozygous retinae (Figure 4d and e).

Collectively, these data indicate that heterozygosity for a Dicer1 mutation promotes the switch from benign retinoma lesions to aggressive and invasive retinoblastomas. Monoallelic loss of Dic is sufficient to promote the expansion of retinal progenitor cells (with a bias toward the amacrine cell fate), which ultimately leads to the formation of early neoplastic lesions that progress into aggressive and metastatic tumors. The ability of these progenitor cells to form these aggressive tumors seems to be a consequence of both increased cell proliferation potential and resistance to apoptosis.

These data strongly support the view that Dicer 1 functions in vivo as a haploinsufficient tumor suppressor gene. Considering that the dysplastic lesions in Chx10Cre; $R b^{\text {lox/lox }} p 107^{/-}$; Dic ${ }^{\text {lox/+ }}$ retinae are observed as early as $\mathrm{P} 35$, it is very unlikely that active selection against complete loss of the remaining wild-type Dic allele is required for tumorigenesis. However, this possibility had to be formally excluded experimentally. As expected, we obtained evidence of Cre-mediated recombination of the conditional Dic allele in Chx10Cre; $R b^{\text {lox/lox }}{\mathrm{p} 107^{-/}}^{-1} \mathrm{Dic}^{\text {lox/+ }}$ normal retinae (Ctr Retinae, P20) and isolated tumors (Figure $5 a$ and b). Importantly, the wild-type allele was retained in all tumors carefully dissected and genotyped (Figure $5 b$ ). To ensure that

a
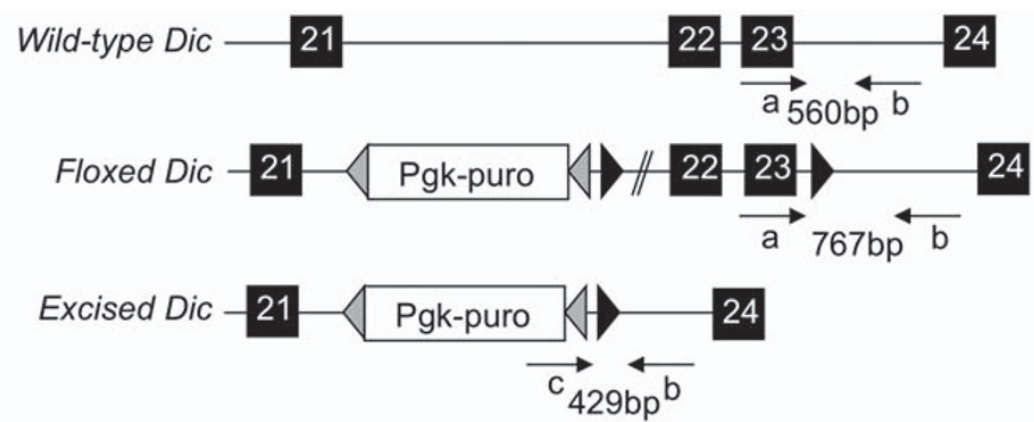

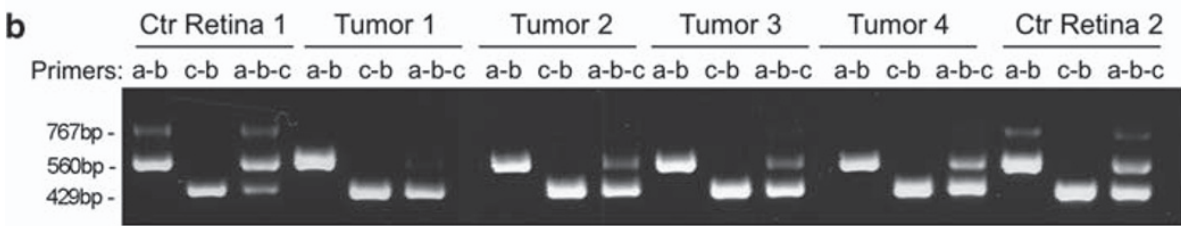

C
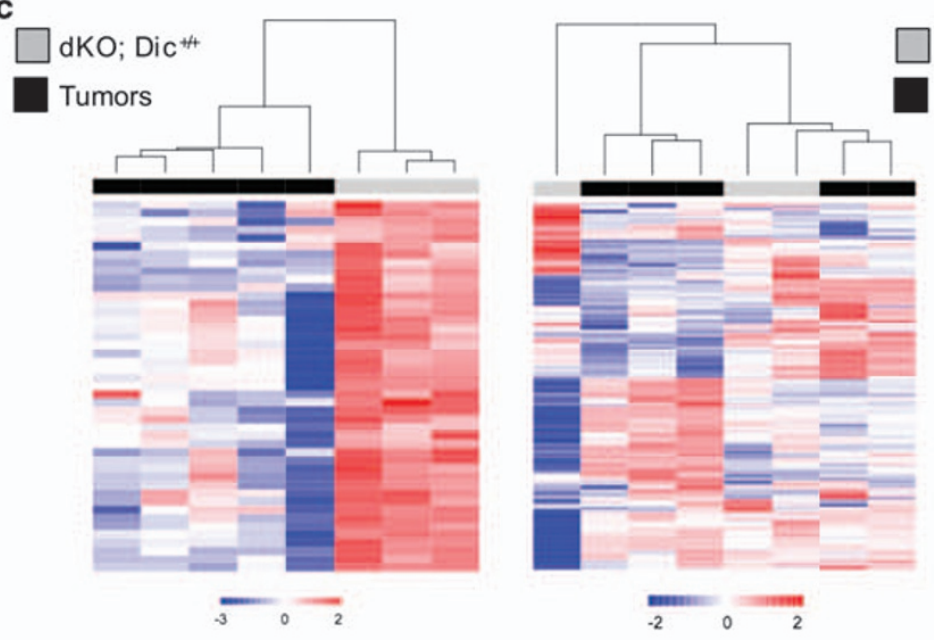

dKO; Dicloxt

Tumors

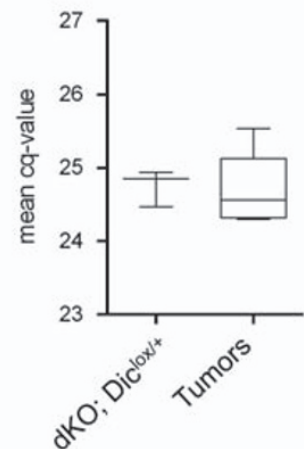

Figure $5 \mathrm{Chx} 10 \mathrm{Cre} ; \mathrm{Rb}^{\mathrm{lox} / \mathrm{lox}} \mathrm{p} 107^{-1-} ; \mathrm{Dic} \mathrm{C}^{\mathrm{lox} /+}$ retinoblastoma tumors retain a wild-type and functional Dic allele. (a) Schematic representation of the Dic wild-type, floxed and Cre-excised alleles. (b) DNA was prepared from two Chx10Cre; $R b^{\text {lox/lox }} p 107^{-1} ;$ Dic ${ }^{\text {lox/+ }}$ P2O retinae (Ctr Retina) and 10 isolated tumors (results from 4 different tumors are shown) and examined by PCR using the primers depicted in the top panel. (c) RT-qPCR analyses of mature miRNA expression. Left panel: hierarchical clustering of

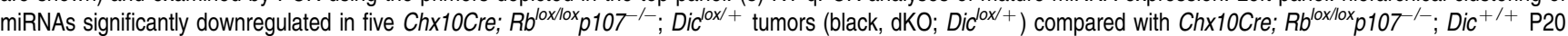
retinae (gray, dKO; $\mathrm{Dic}^{+/+}$). Middle panel: heat map of all miRNAs expressed at higher levels than the mean in Chx $10 \mathrm{Cre} ; \mathrm{Rb}^{\text {lox/lox}} \mathrm{p} 107^{-1-}$; Did $\mathrm{D}^{\mathrm{lox} /+}$ P20 retinae shows

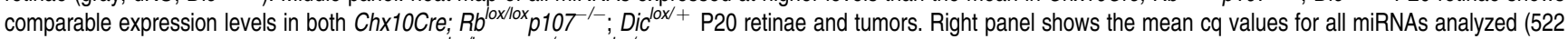

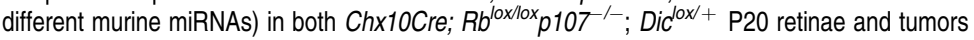


the remaining Dic allele was not functionally inactivated through mutations, we assessed the expression levels of all mature miRNAs in five different Chx10Cre; $R b^{\text {lox/lox }} \mathrm{p} 107^{-1-}$; $\mathrm{Dic}^{\mathrm{lox} /+}$ tumors by RT-qPCR analysis. Consistent with a decrease of Dicer1 function, we observed a global decrease in steady-state miRNA levels in all five tumors analyzed

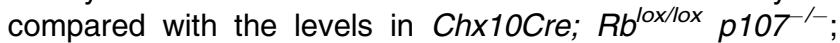
Dic $^{+/+}$(Figure 5c, left panel). Importantly, all mature miRNAs that are expressed at high levels in Chx10Cre; $R b^{\text {lox/lox }}$ $p 107^{-1-} ; \mathrm{Dic}^{\mathrm{lox} /+} \mathrm{P} 20$ retinae are expressed at comparable levels in all five tumors (Figure $5 \mathrm{c}$, right panels). These analyses indicate that microRNA processing is only partly impaired, but not completely disrupted, in these tumors. Finally, we directly assessed the consequences of complete Dicer1 inactivation in the retinoblastoma mouse model. We confirmed that complete ablation of Dicer 1 in the retina is well tolerated and only leads to progressive retinal degeneration. ${ }^{16}$ Similar results were obtained on the retinoblastoma-sensitized background. The retinae of adult Chx10Cre; $R b^{\text {lox/lox }}$ $p_{107^{-1-}}$; Dic ${ }^{\text {lox/lox }}$ were partly dis-organized (Lambertz et al., manuscript in preparation). Surprisingly, these mice were protected from tumor formation Figure 2a). Together, the data argue that although partial loss of Dicer function favors tumor formation, complete loss of Dicer is deleterious to retinoblastoma development, further arguing in favor of a haploinsufficient tumor suppressor function of Dicer1.

These data also imply that a set of miRNAs, the function of which requires Dicer1 function, might act to prevent full-blown retinoblastoma formation on the Chx10Cre; $R b^{\text {lox/lox }} p 107^{/-}$ background. To identify such candidate tumor suppressor miRNAs, we determined the expression profile of the entire miRNome in P20 retinae from wild-type (Cre-negative), Chx10Cre; $\mathrm{Rb}^{\text {loxllox }} \mathrm{p107^{-1 }} ; \mathrm{Dic}^{+/+}$and Chx10Cre; $R b^{\text {lox/lox }} p 107^{-/-} ;$Dic ${ }^{\text {lox/+ }}$ using LNA-based microarray and RT-qPCR approaches. Both types of analyses identified a common set of 11 miRNAs that are consistently upregulated between wild-type and Chx10Cre; $\mathrm{Rb}^{\text {lox/lox }} \mathrm{p} 107^{-/-} ; \mathrm{Dic}^{+/+}$ (Figure 6a). Most interestingly, among them are two members of the let-7 family (let-7c and let7i), the upregulation of which and of another let-7 member, let-7b, was confirmed by independent Q-RT-PCR analysis (Figure 6b). Given that this upregulation was significantly attenuated in the Dic heterozygous retinae and the recognized role of let-7 family members in tumor suppression, ${ }^{28}$ this observation raises the possibility that let-7 family members have a causal role in retinoblastoma formation as critical regulators of the switch from retinomas to retinoblastoma. Our list of 11 differentially expressed miRNAs also included miR-34c (Figure 6a and b). There was also a clear upregulation of miR-34b-3p in both microarray and RT-q-PCR analyses, and a moderate, but reproducible, upregulation of $\mathrm{miR}-34 \mathrm{a}$ was evident from the microarray data (data not shown). Interestingly, the miR-34 family members have been identified as p53 targets and key mediators of its tumor suppressor function. ${ }^{29}$

\section{Discussion}

To address the importance of Dicer1 gene dosage in cancer development, we used a preclinical mouse model of retino- blastoma. ${ }^{17}$ Our data provide clear genetic evidence that Dicer1 functions as a haploinsufficient tumor suppressor in vivo. In keeping with this observation, information in the public domain, for example, Cancer Genome Project at the Sanger Institute, ${ }^{30}$ indicates that hemizygous deletions of DICER1 occur in $27 \%(207 / 761)$ of tumors derived from tissues of diverse origins, such as the central nervous system, lung, pancreas, soft tissues, breast, bone, hematopoietic or lymphoid. Importantly, consistent with our findings, homozygous deletions have never been observed in any of these 761 tumors. Very recently, heterozygous point mutations in DICER1 were reported in patients with pleuropulmonary blastoma. ${ }^{31}$ However, DICER1 expression was retained in the mesenchymal tumor cells from these patients, again arguing against strong selective pressure for complete loss of Dicer function in human tumors. Thus, although this study focuses on the role of Dicer1 in a mouse model of retinoblastoma, there is evidence supporting a broad role for DICER1 as a haploinsufficient tumor suppressor in human cancer.

Kumar et al. had attempted to investigate an etiological role for Dicer1 in a mouse model of cancer, in which Dicer1 was inactivated in a K-Ras-induced mouse model of lung cancer using intranasal infection with adenovirus expressing Cre. ${ }^{8}$ Although it highlighted an important role for Dicer1 in tumor suppression, this elegant study did not resolve the important issue of gene dosage. The authors had shown that tumorigenesis was enhanced on both $\mathrm{Dic}^{\mathrm{lox} /+}$ and Dic ${ }^{\text {loxlox }}$ genetic backgrounds, but they did not analyze the extent of Cre-mediated Dicer1 inactivation in these tumors. It therefore remained formally possible that lung tumors developed in the Dic ${ }^{\text {loxlox }}$ mice only as a result of incomplete inactivation of Dicer1 function. This possibility has just very recently been confirmed in a study that was published while our manuscript was being processed. ${ }^{32}$ This last report, together with the data presented herein, clearly emphasizes that only partial, rather than complete, inactivation of Dicer1 enhances tumorigenesis in vivo (Figure 7).

It is generally accepted that complete loss of tumor suppressor function through mutations and loss of heterozygosity is a prerequisite for tumor development. To date, however, several haploinsufficient tumor suppressor genes have been identified, ${ }^{33}$ mostly through the use of genetically engineered mouse models. Our mouse genetic data identify DICER1 as yet another member of this group. A general theme in haploinsufficient genes is that tumors generated in a haploinsufficient context are frequently of later onset and less severe than the corresponding tumor carrying the homozygously mutated gene. This is not the case for Dicer1. Complete loss of Dicer1 did not enhance but rather inhibited retinoblastoma formation. In agreement with this, biallelic loss of Dicer 1 was strongly selected against in K-Ras-induced lung tumors. $^{32}$ To our knowledge, Dicer1 is therefore the first example of a gene that functions as a tumor suppressor only in the context of haploinsufficiency and not on homozygous loss of function. Regardless, as the list of haploinsufficient tumor suppressors grows, hemizygous deletions at loci such as DICER1 should be considered as potential key pro-tumorigenic lesions. 

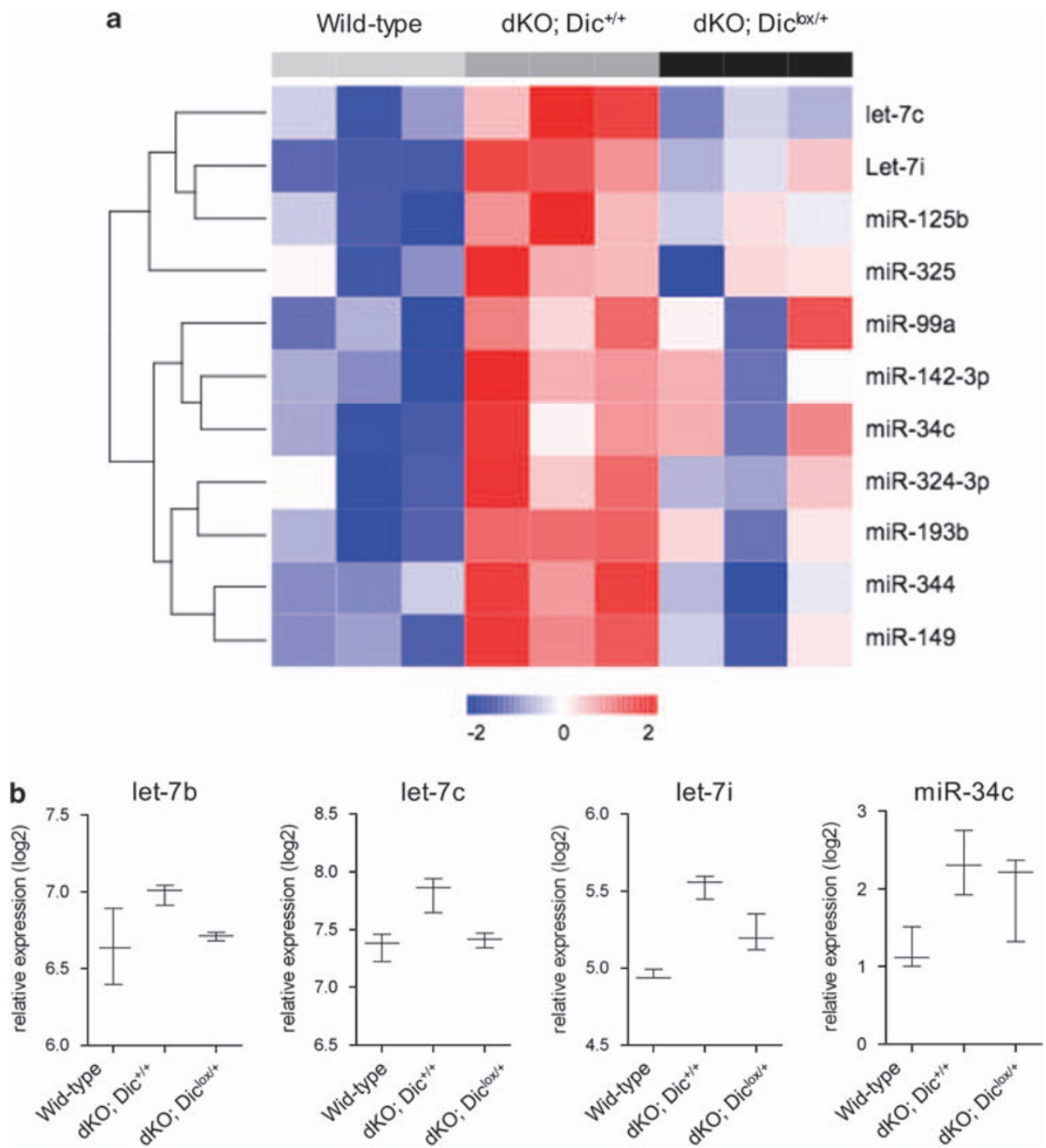

Figure 6 Search for putative tumor suppressor miRNAs in retinoblastoma. (a) Heat map of selected differentially expressed miRNAs in Chx10Cre-negative mice (light

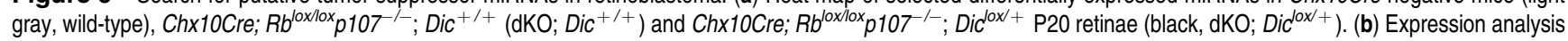
by RT-qPCR of let-7 family members (let-7b, let-7c and let-7i) and miR-34c

Our data further establish a causative link between global downregulation of miRNA-processing and cancer development. It is possible that the reduction of expression of only a subset of tumor suppressor miRNAs is the event that promotes tumorigenesis (Figure 7). In the context of retinoblastoma, our profiling data identified the let-7 family members as potential candidate tumor suppressors. It may be noted that let-7b has previously been shown to be downregulated in human retinoblastoma. ${ }^{34}$ Other sets of miRNAs that can account for the observed tumor-suppressive activity of Dicer1 in retinoblastoma are the miR-34 family members. Given that these genes have been identified as p53 targets and are critical mediators of its activity ${ }^{29}$ and the importance of the p53 tumor suppressor function in retinoblastoma, ${ }^{17,21}$ it will be interesting to further assess genetically their functional relevance in the retinoblastoma mouse model. It has been shown that miR-34 family members are differentially expressed in human retinoblastoma cell lines and tumors compared with normal retina samples. ${ }^{35}$ Exogenous miR-34a inhibited cell growth and/or increased apoptosis in retinoblastoma cell lines (Y79, Weri-Rb1). ${ }^{35}$ Together, these data identify the miR-34 family members as potential therapeutic targets for retinoblastoma. Interestingly, among the common putative mRNA targets of both let-7 and miR-34 family members is the N-myc oncogene. N-myc is indeed a validated miR-34a target (http://mirecords.umn.edu/miRecords/) and is a predicted target of let-7i (http://www.targetscan.org/). This gene is amplified in another mouse model of retinoblastoma ${ }^{36}$ and in approximately $10 \%$ of human retinoblastomas. ${ }^{37}$ These observations raise the possibility that members of both let-7 and miR34 families cooperate to restrain N-Myc oncogenic function in retinoblastoma.

Finally and importantly, our data argue against the development of DICER1-inactivating molecules as anticancer drugs. Indeed, even if complete Dicer1 inactivation seems to 


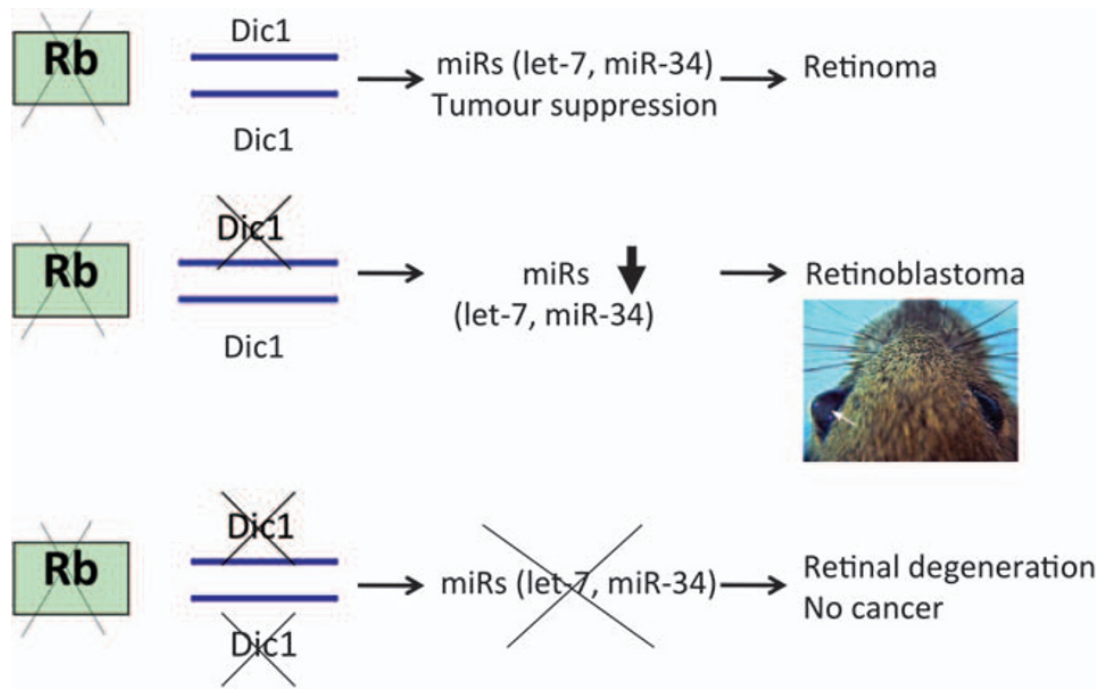

Figure 7 Monoallelic loss of Dicer enhances retinoblastoma formation. Our data support a model in which monoallelic loss of Dicer1 cooperates with Rb inactivation in the formation of aggressive and invasive retinoblastoma. In contrast, biallelic loss of Dicer1 leads to retinal degeneration on a retinoblastoma-sensitized background and inhibition of tumor formation

be deleterious for cancer development its partial inactivation promotes, rather than inhibits, tumor formation.

\section{Materials and Methods}

Mice. All animal experiments were performed in accordance with the guidelines of the University of Ghent Animal Care and Use Ethics Committee. BrdU $(100 \mu \mathrm{g} / \mathrm{g}$ of body weight) was injected intraperitoneally $1 \mathrm{~h}$ before killing.

Immunohistochemistry. Eyes were fixed overnight in $4 \%$ paraformaldehyde/PBS, and paraffin embedded. Sections of $5 \mu \mathrm{m}$ thickness were immunostained with the following antibodies: GFP (Santa Cruz Biotechnology, Santa Cruz, CA, USA, 1/100); BrdU (BD Pharmingen, San Jose, CA, USA, 1/10); Ki-67 (DAKO, Glostrup, Denmark, 1/30); cleaved caspase-3 (Cell Signaling, Danvers, MA, USA, 1/100); syntaxin (Sigma, St Louis, MO, USA, 1/20 000); calretinin (Millipore, Billerica, MA, USA, 1/700); Chx10 (Exalpha Biologicals, Shirley, MA, USA, 1/100).

Recombination analysis. DNA was isolated from dissected retinae and isolated tumors using the DNeasy Blood \& Tissue Kit (Qiagen, Germantown, MD, USA). Dicer1 recombination was analyzed by PCR using the following primers: primer a $5^{\prime}$-ATTGTTACCAGCGCTTAGAATTCC; primer c $5^{\prime}$-TCG GAATAGGAACTTCGTTTAAAC; and the reverse $b$ primer $5^{\prime}$-GGGAGGT GTACGTCTACAATT. PCR conditions were as follows: $1 \times$ precycle at $94^{\circ} \mathrm{C}$ for $3 \mathrm{~min}$ and 30 cycles of $94^{\circ} \mathrm{C}, 30 \mathrm{~s} ; 60^{\circ} \mathrm{C}, 30 \mathrm{~s} ; 72^{\circ} \mathrm{C}, 45 \mathrm{~s}$.

microRNA expression analyses. Total RNA was prepared from dissected retinae or isolated tumors using the miRNeasy kit (Qiagen) according to the manufacturer's instructions. Profiling of these samples was performed by both microarray (miRCURY LNA Array, Exiqon, Vedbaek, Denmark) and qPCR. The RTqPCR expression profiling of 522 murine miRNAs and subsequent data normalization were performed as described previously. ${ }^{38,39}$ Differential miRNA expression was evaluated using Student's $t$-test. Hierarchical clustering was performed using Ward's method and Manhattan distance using R Bioconductor software (Oxford, UK).

\section{Conflict of interest}

The authors declare no conflict of interest.
Acknowledgements. We thank Natalie Farla and Rose Van Isacker for their excellent technical assistance. We thank $G$ Hannon for providing the Dic floxed mince. J-C Marine received support from the EMBO Young Investigator program. This work was supported in part by Geconcerteerde Onderzoek Aangelegenheden (GOA, University Ghent, Belgium) and EU (FP7 Program, ONCOMIRs, Contract no. 201102). This publication reflects only the authors' views. The commission is not liable for any use that may be made of the information herein.

1. Croce CM. Causes and consequences of microRNA dysregulation in cancer Nat Rev Genet 2009; 10: 704-714.

2. Bartel DP. MicroRNAs: target recognition and regulatory functions. Cell 2009; 136 : 215-233.

3. Ventura A, Jacks T. MicroRNAs and cancer: short RNAs go a long way. Cell 2009; 136 586-591.

4. Esquela-Kerscher A, Trang P, Wiggins JF, Patrawala L, Cheng A, Ford $L$ et al. The let-7 microRNA reduces tumor growth in mouse models of lung cancer. Cell Cycle 2008; 7 : 759-764.

5. Kumar MS, Erkeland SJ, Pester RE, Chen CY, Ebert MS, Sharp PA et al. Suppression of non-small cell lung tumor development by the let-7 microRNA family. Proc Natl Acad Sci USA 2008; 105: 3903-3908.

6. Esquela-Kerscher A, Slack FJ. Oncomirs - microRNAs with a role in cancer. Nat Rev Cancer 2006; 6: 259-269.

7. Lu J, Getz G, Miska EA, Alvarez-Saavedra E, Lamb J, Peck D et al. MicroRNA expression profiles classify human cancers. Nature 2005; 435: 834-838.

8. Kumar MS, Lu J, Mercer KL, Golub TR, Jacks T. Impaired microRNA processing enhances cellular transformation and tumorigenesis. Nat Genet 2007; 39: 673-677.

9. Chang TC, Yu D, Lee YS, Wentzel EA, Arking DE, West KM et al. Widespread microRNA repression by Myc contributes to tumorigenesis. Nat Genet 2008; 40: 43-50.

10. Pampalakis G, Diamandis EP, Katsaros D, Sotiropoulou G. Down-regulation of dice expression in ovarian cancer tissues. Clin Biochem 2009; e-pub ahead of print 25 September 2009.

11. Karube $\mathrm{Y}$, Tanaka H, Osada H, Tomida S, Tatematsu Y, Yanagisawa $\mathrm{K}$ et al. Reduced expression of Dicer associated with poor prognosis in lung cancer patients. Cancer $\mathrm{Sc}$ 2005; 96: 111-115.

12. Melo SA, Ropero S, Moutinho C, Aaltonen LA, Yamamoto H, Calin GA et al. A TARBP2 mutation in human cancer impairs microRNA processing and DICER1 function. Nat Genet 2009; 41: 365-370.

13. Bernstein E, Kim SY, Carmell MA, Murchison EP, Alcorn H, Li MZ et al. Dicer is essentia for mouse development. Nat Genet 2003; 35: 215-217.

14. Murchison EP, Partridge JF, Tam OH, Cheloufi S, Hannon GJ. Characterization of Dicerdeficient murine embryonic stem cells. Proc Natl Acad Sci USA 2005; 102: 12135-12140.

15. Rowan S, Cepko CL. Genetic analysis of the homeodomain transcription factor $\mathrm{Chx10}$ in the retina using a novel multifunctional BAC transgenic mouse reporter. Dev Biol 2004; 271: 388-402.

16. Damiani D, Alexander JJ, O'Rourke JR, McManus M, Jadhav AP, Cepko CL et al. Dicer inactivation leads to progressive functional and structural degeneration of the mouse retina. J Neurosci 2008; 28: 4878-4887. 
17. Zhang J, Schweers B, Dyer MA. The first knockout mouse model of retinoblastoma. Cell Cycle 2004; 3: 952-959.

18. Donovan SL, Schweers B, Martins R, Johnson D, Dyer MA. Compensation by tumor suppressor genes during retinal development in mice and humans. BMC Biol 2006; 4 : 14.

19. Zhang J, Gray J, Wu L, Leone G, Rowan S, Cepko CL et al. Rb regulates proliferation and rod photoreceptor development in the mouse retina. Nat Genet 2004; 36: 351-360.

20. DiCiommo D, Gallie BL, Bremner R. Retinoblastoma: the disease, gene and protein provide critical leads to understand cancer. Semin Cancer Biol 2000; 10: 255-269.

21. Laurie NA, Donovan SL, Shih CS, Zhang J, Mills N, Fuller C et al. Inactivation of the p53 pathway in retinoblastoma. Nature 2006; 444: 61-66.

22. Marine JC, Dyer MA, Jochemsen AG. MDMX: from bench to bedside. J Cell Sci 2007; 120 (Pt 3): 371-378.

23. Dyer MA, Cepko CL. p27Kip1 and p57Kip2 regulate proliferation in distinct retinal progenitor cell populations. J Neurosci 2001; 21: 4259-4271.

24. Yuge K, Nakajima M, Uemura Y, Miki H, Uyama M, Tsubura A. Immunohistochemical features of the human retina and retinoblastoma. Virchows Arch 1995; 426: 571-575.

25. Alexiades MR, Cepko CL. Subsets of retinal progenitors display temporally regulated and distinct biases in the fates of their progeny. Development 1997; 124: 1119-1131.

26. Liu IS, Chen JD, Ploder L, Vidgen D, van der Kooy D, Kalnins VI et al. Developmental expression of a novel murine homeobox gene (Chx10): evidence for roles in determination of the neuroretina and inner nuclear layer. Neuron 1994; 13: 377-393.

27. Burmeister M, Novak J, Liang MY, Basu S, Ploder L, Hawes NL et al. Ocular retardation mouse caused by Chx10 homeobox null allele: impaired retinal progenitor proliferation and bipolar cell differentiation. Nat Genet 1996; 12: 376-384

28. Bussing I, Slack FJ, Grosshans H. let-7 microRNAs in development, stem cells and cancer. Trends Mol Med 2008; 14: 400-409.
29. He L, He X, Lowe SW, Hannon GJ. microRNAs join the p53 network-another piece in the tumour-suppression puzzle. Nat Rev Cancer 2007; 7: 819-822.

30. Forbes SA, Bhamra G, Bamford S, Dawson E, Kok C, Clements J et al. The catalogue of somatic mutations in cancer (COSMIC). Curr Protoc Hum Genet 2008; Chapter 10 Unit 1011.

31. Hill DA, Ivanovich J, Priest JR, Gurnett CA, Dehner LP, Desruisseau D et al. DICER1 mutations in familial pleuropulmonary blastoma. Science 2009; 325: 965.

32. Kumar MS, Pester RE, Chen CY, Lane K, Chin C, Lu J et al. Dicer1 functions as a haploinsufficient tumor suppressor. Genes Dev 2009; 23: 2700-2704.

33. Santarosa M, Ashworth A. Haploinsufficiency for tumour suppressor genes: when you don't need to go all the way. Biochim Biophys Acta 2004; 1654: 105-122.

34. Huang JC, Babak T, Corson TW, Chua G, Khan S, Gallie BL et al. Using expression profiling data to identify human microRNA targets. Nat Methods 2007; 4: 1045-1049.

35. Dalgard CL, Gonzalez M, deNiro JE, O'Brien JM. Differential microRNA-34a expression and tumor suppressor function in retinoblastoma cells. Invest Ophthalmol Vis Sci 2009; 50: 4542-4551

36. MacPherson D, Conkrite $\mathrm{K}$, Tam M, Mukai S, Mu D, Jacks T. Murine bilateral retinoblastoma exhibiting rapid-onset, metastatic progression and $\mathrm{N}$-myc gene amplification. EMBO J 2007; 26: 784-794.

37. Lee WH, Murphree AL, Benedict WF. Expression and amplification of the N-myc gene in primary retinoblastoma. Nature 1984; 309: 458-460.

38. Mestdagh $P$, Van Vlierberghe $P$, De Weer A, Muth D, Westermann F, Speleman F et al. A novel and universal method for microRNA RT-qPCR data normalization. Genome Biol 2009; 10: R64.

39. Mestdagh P, Feys T, Bernard N, Guenther S, Chen C, Speleman F et al. High-throughput stem-loop RT-qPCR miRNA expression profiling using minute amounts of input RNA. Nucleic Acids Res 2008; 36: e143. 